\title{
A reasonable Response to Diphensiprone in Pediatric Alopecia Patient: A Case Report
}

\section{Selma Bakar DERTLIOOĞLU}

Department Of Dermatology, SBU Fethi Sekin City Hospital, Elazığ, Turkey.

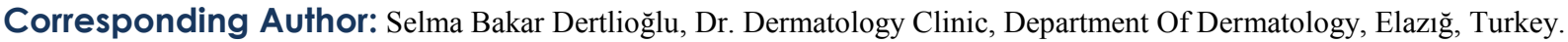

Received date: January 16, 2021; Accepted date: January 23, 2021; Published date: March 11, 2021

Citation: Selma Bakar Dertlioğlu (2021) A reasonable Response to Diphensiprone in Pediatric Alopecia Patient: A Case Report. Clini Case Repo and Stud 2(1); DOI: 10.31579/2690-8808/058

Copyright: ( ) 2021, Selma Bakar Dertlioğlu, This is an open access article distributed under the Creative Commons Attribution License, which permits unrestricted use, distribution, and reproduction in any medium, provided the original work is properly cited.

\section{Abstract has not yet been fully elucidated. to use diphencyprone (DPCP). effective and with less side effects. \\ Keywords: alopecia, immunotherapy, difensipron (DPCP) \\ Running title:Diphensiprone in Alopecia Patient}

Alopecia areata (AA) is an autoimmune disorder which accounts for the most frequent cause of inflammation based hair loss among dermatological outpatient attendances. It has an unpredictable course and its etiology

Many alternatives treatments are available; however, none of them have been curative or preventive so far. Its treatment must be individualized, and aims at suppressing the phase of activity of the disease. Alopecia areata (AA) persistent for a minimum of 6 months and resistant to other treatments and/or severe AA are indications

We report a 9 year-old boy with diffuse alopecia areata, who underwent topical immunotherapy with diphencyprone. The application procedures, the results obtained and the clinical follow-up are described.

Treatment alternatives should be tried, especially in the pediatric age group, due to the prominent effects of the disease on the patient's quality of life and consequent development of psychological impairments. In this case; DPCP application is a preferable treatment option in AA in the pediatric age group because is very easy,

\section{Introduction}

Alopecia Areata (AA) is a systemic, autoimmune condition characterized by loss of hair, without any association with scarring or inflammatory processes. [1]. Its course is unpredictable, and the response to treatments is extremely variable. The worldwide prevalence of AA ranges from $0.1 \%$ to $0.2 \%$. Its etiology remains uncertain; it is known that influenced by genetics, autoimmune and environmental factors [1]

The diagnosis of AA is made by clinical; trichoscopy and anatomopathological examination. During the trichoscopy it is possible to find black dots, yellow dots and exclamation mark hairs. In the anatomopathological examination, in the acute phase, there is lymphocytic infiltrate (CD4+ T and CD8+T) peribulbar in anagen hairs, with a "swarm of bees" aspect [1]. The treatment for AA is aimed at suppressing the activity phase. DPCP is a topical sensitizer that causes allergic contact dermatitis by acting as a hapten. Also DPCP is believed to have a variety of immunomodulatory effects [1]

\section{Case Report}

Herein we report a 9-year-old male patient presenting with widespread loss of hair. The patient has hair loss for about 3 years. In his dermatological examination; there were diffuse hair loss involving almost the entire scalp. Eyebrows and eyelashes were intact, no erythema on the scalp and no palpable lymph nodes. There were few pitting on the nails. Teeth were normal. Also hairs with exclamation marks were seen on dermoscopy.

There was no evidence of atopic dermatitis or autoimmune thyroid disease with a positive family history in the patient's history. All laboratory evaluations were normal. The patient was previously clinically diagnosed with AA. Various treatments have been tried, such as the topical steroid, minoxidil solution; systemic corticosteroids and immunosuppressive treatments were previously tried on the patient. Results of all treatments were almost similar and responses were short-lived. When he applied to us, he stopped his last treatment (systemic corticosteroids) 3 months ago. Shortly after he stopped treatment, his hair fell out again. In the meeting we held with his mother when they applied to our polyclinic she stated that; hair loss caused great distress in the patient's life both at school and at home, he did not want to go to school and that he always wore a hat. After photographic documentation of the lesions and after discussing about treatment alternatives, we decide to apply topical diphencyprone (DPCP) with the patient and his mother. Because the patient's percentage of involvement was high and he was resistant to other classical treatments 
We used DPCP in acetone vehicle. We were performed the applications on the scalp with swab soaked in the solution. The first application (sensitization) was performed with $2 \%$ DPCP, in a $2 \mathrm{~cm}$ diameter area. After two weeks, adequate response was observed (mild erythema and mild pruritus in the treated area), and weekly applications ipsilateral to the sensitized side begun with $0.001 \%$ DPCP. The concentration of the substance was gradually increased up during each application $(0.001 \%$, $0.025 \%, 0.05 \%, 0.1 \%$ ) until the patient had a more intense response than the one defined as adequate. At this point, the concentration was established for the patient, and the treatment continued with weekly applications. After the appearance of re-epilation on the side initially treated, bilateral treatment was started.

After four months of continuous DPCP treatment, our patient's scalp showed hair regrowth. Hair growth was observed first in the temporal and frontal areas and finally in the occipital area. Hair density in sparse eyebrows and eyelashes were increased. The patient had side effects in the form of mild erythema, itching, vesicle, cervical and occipital lymphadenopathy. Most of these reactions regressed spontaneously within an average of two weeks, with a one-week break from the application, without requiring treatment. No problem was encountered during his follow-up. About $90 \%$ of the hair had grown in the 30th week of treatment. Unfortunately, the patient, whose treatment was continuing and was planned to undergo maintenance treatment left our follow-up because he had to change the city.

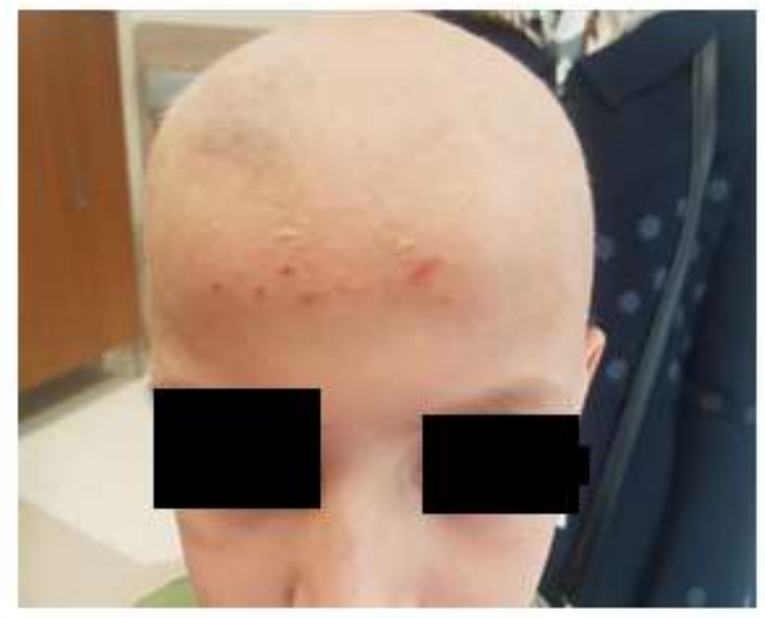

Figure 1. Hair loss in the frontal area.

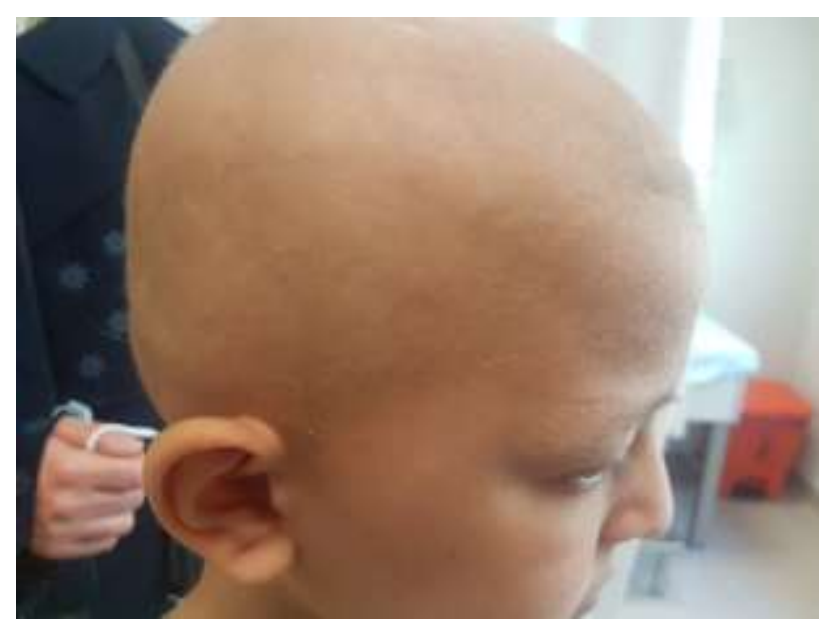

Figure 2. Widespread hair loss over the entire scalp.

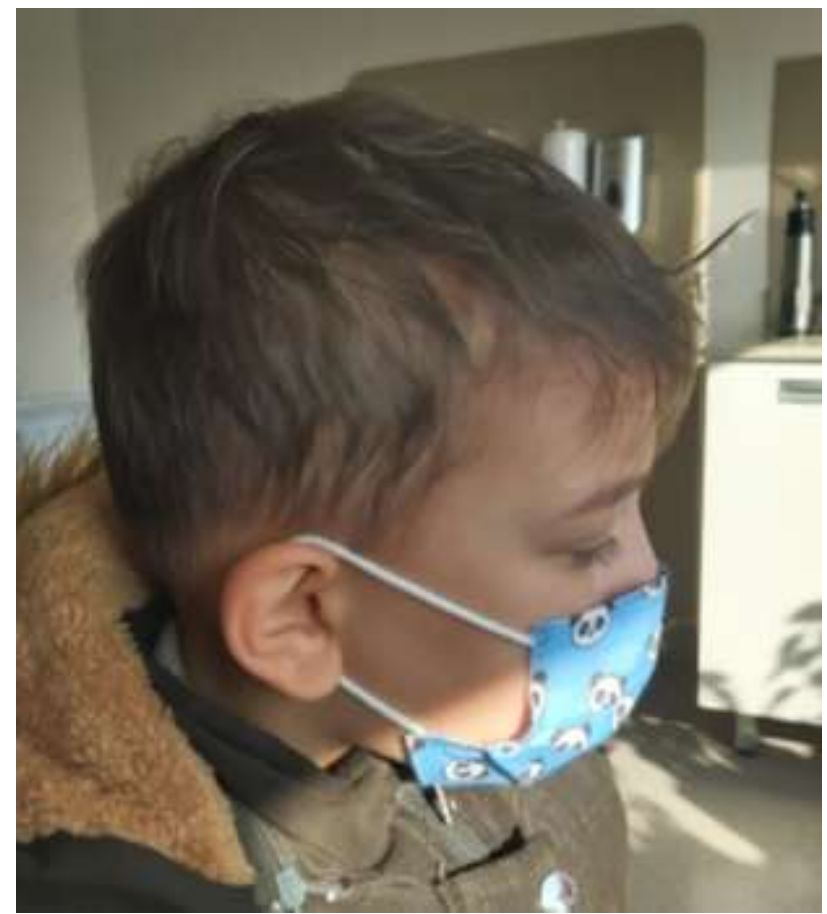

Figure 3. Hair growth in the temporal and frontal areas.

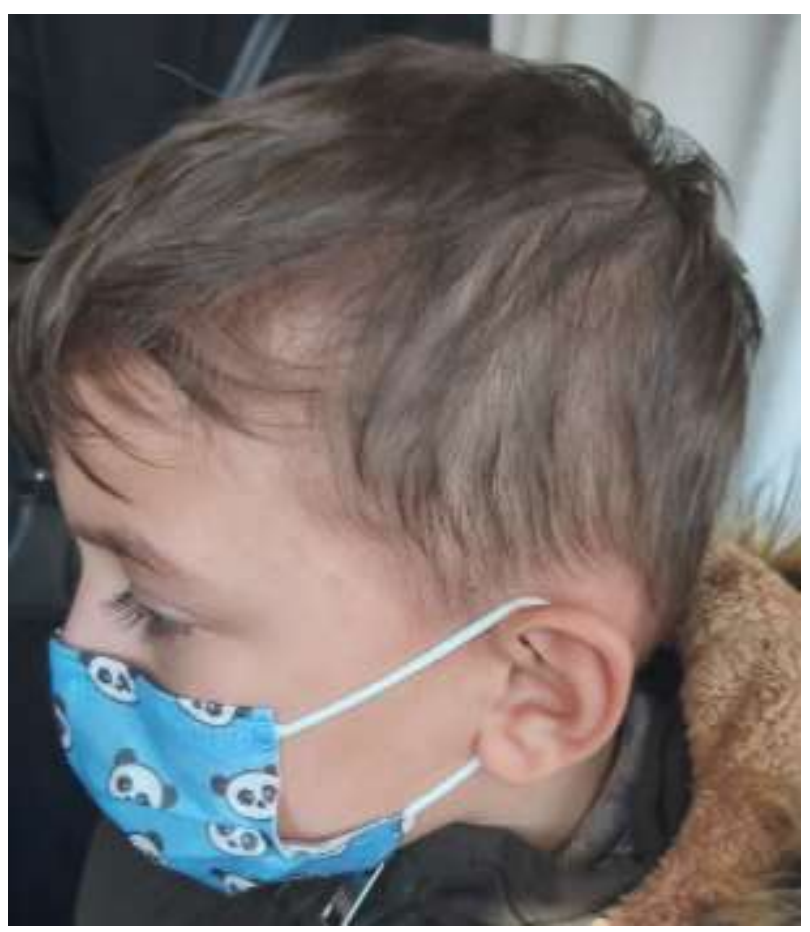

Figure 4. Increased hair on eyebrows and eyelashes.

\section{Discussion}

Alopecia areata is a relatively common condition. It does not pose a threat to life, but it causes psychological stress and impacts on the quality of life [2]. Its treatment is determined by the patient's age and the condition's degree of involvement [1].

The use of DPCP in the treatment of AA was described in 1983 by Happle et al. and several studies $[3,4,5]$ have proven its efficacy [3]. Different results have been obtained in different studies. The changes in response 
rates may be due to the number of patients in trials, the type, duration and severity of the alopecia areata, and different methods of assessing clinical efficacy [4-10].

In general, adverse effects warranting discontinuation of DPCP treatment were not common. The most commonly reported side effects are pruritus, local eczema, servical and occipitale lymphadenopathy, and contact dermatit. Rarely observed are vitiligo and dyschromia. The development of these side effects in the treated area was considered as an indicator of successful sensitization $[5,7,8]$.

Data regarding the efficacy of DPCP immunotherapy is variable. In a study, the response rates have been reported respectively; $17 \%$ for alopecia totalis / universalis, $60 \%$ for $75 \%-100 \%$ hair loss and it is $100 \%$ for hair loss below $50 \%$. In children with severe alopecia areata these rates were $27 \%-33 \%$. Recurrence often occurs when treatment is discontinued [4].

The largest clinical trial ever performed showed a total success rate of $60 \%$; however, among those with Alopecia Totalis / Alopecia Universalis, this rate was $17.4 \%[6]$.

In another study in pediatric patients concluded that; approximately onethird of children in this study showed improvement in hair density with DPCP treatment. However, the response dropped off at between 6 months and 1 year of treatment, and overall, only $10 \%$ of their patients had complete hair regrowth [9].

Generally, patients with widespread AA, or patients who are resistant to other known treatment options are very eager to introduce new therapies. The response time to DPCP immunotherapy may extend up to two years in some cases, which can be a significant disadvantage that may limit the use of treatment. In addition to the advantages such as having few side effects, being easy to apply, being an effective treatment, it has disadvantages such as long treatment period.

\section{Conclusion}

Considering the psychosocial effects of the disease on patients and the side effects of systemic treatments especially in diffuse hair loss, we think that DPCP treatment is a good option for patients primarily in the childhood age group.

\section{Conflict of Interest}

No conflict of interest.

\section{References}

1. Tonso TM, Romanelli C, Alves RAR, Mendes C, Oliveira AHK. (2016) Topical immunotherapy in the treatment of alopecia areata: the importance of the maintenance phase - report of two cases. Surg Cosmet Dermatol; 8: 52-55.

2. Islam N, Leung PSC, Huntley AC, Gershwin ME. (2015) The autoimmune basis of alopecia areata: a comprehensive review. Autoimmun Rev. 14(2): 81-89.

3. Happle R, Hausen BM, Wiesner-Menzel L. (1983) Diphencyprone in the treatment of alopecia areata. Acta Derm Venereol. 63(1): 49-52.

4. Gilhar A, Etzioni A, Paus R: (2012) Alopecia areata. N Eng J Med. 366: 1515-1525.

5. Donovan J, Salsberg JM. (2012) The safety and efficacy of diphencyprone for the treatment of alopecia areata in children. Arch Dermatol. 148(9): 1084-1085.

6. El-Zawahry BM, Azzam OA, Zaki NS, Abdel-Raheem HM, Bassiouny DA. (2013) PTPN22 gene polymorphism in Egyptian alopecia areata patients and its impact on response to diphencyprone immunotherapy. Gene. 523(2): 147-151.

7. Durdu M, Özcan D, Baba M, Seçkin D. (2015) Efficacy and safety of diphenylcyclopropenone alone or in combination with anthralin in the treatment of chronic extensive alopecia areata: A retrospective case series. J Am Acad Dermatol. 72(4): 640-650.

8. Chiang KS, Mesinkovska NA, Piliang MP, Bergfeld WF. (2015) Clinical Efficacy of Diphenylcyclopropenone in Alopecia Areata: Retrospective Data Analysis of 50 Patients. J Investig Dermatol Symp Proc. 17(2): 50-55.

9. Jennifer M. Salsberg, Jeff Donovan. (2012) The Safety and Efficacy of Diphencyprone for the Treatment of Alopecia Areata in Children Arch Dermatol. 148(9): 1084-1085. doi:10.1001/archdermatol.2012.16221

10. Xiao FL, Yang S, Liu JB, et al (2006) The epidemiology of childhood alopecia areata in China: a study of 226 patients. Pediatr Dermatol. 23: 13-8. 